\title{
Carotid-Cavernous Fistula in the Emergency Department
}

\author{
Acil Serviste Karotikokavernöz Fistül Olgusu
}

Mehtap Gürger, Evren Ekingen, Metin Ateşçelik, Ömer Doğan Alataş, Mustafa Yıldız

Department of Emergency Medicine, Faculty of Medicine, Fırat University, Elazığ, Turkey

\section{ABSTRACT}

Introduction: A carotid-cavernous fistula results from abnormal communication between the internal or external carotid arteries and the cavernous sinus. It occurs because of traumatic or spontaneous rents. Seventy-five percent of the cases are traumatic. The etiology of spontaneous fistula is unknown but is thought to occur as a result of rupture of an arteriovenous malformation. Spontaneous fistula usually occurs in middle-aged or elderly women. Atherosclerosis, systemic hypertension, collagen vascular disease, pregnancy, connective tissue disease, and minor trauma may be predisposing factors in the development of spontaneous carotid-cavernous fistula. The clinical presentations of patients are pulsating or nonpulsatile exophthalmus, chemosis, reduced eye movements, blurred vision, seconder glaucoma, murmur, tinnitus, and headache.

Case Report: In this report, a 45-year-old female patient with a spontaneous carotid-cavernous fistula that developed after severe headache, nausea, and vomiting is presented.

Conclusion: Carotid-cavernous fistula is a disease that is rarely seen and difficult to diagnosis and needs to be considered in the emergency department; it can be treated profoundly with early diagnosis and treatment.

Keywords: Carotid-cavernous fistula, emergency department

Received: 14.02.2013 Accepted: 19.07.2013

\section{ÖZET}

Giriş: Karotiko-kavernöz sinüs fistül internal veya eksternal karotis arterle kavernöz sinüsün anormal bağlantısı sonucu oluşur. Karotikokavernöz fistüller travmatik veya spontan oluşabilir. Vakaların \%75'i travmatiktir. Spontan fistüllerin etiyolojisi tam bilinmemekle birlikte arteriyovenöz malformasyon rüptürü sonucu oluştuğu düşünülmektedir. Spontan fistüller genellikle orta ve ileri yaş bayanlarda oluşur ve gelişiminde ateroskleroz, sistemik hipertansiyon, kollajen vasküler hastalıklar, gebelik, konnektif doku hastalığı ve minör travma predispozan faktör olabilir. Hastaların kliniğinde pulsatif veya nonpulsatif ekzoftalmi, kemozis, göz hareketlerinde azalma, görme bozukluğu, sekonder glokom, üfürüm, kulak çınlaması ve baş ağrısı vardır.

Olgu Sunumu: Bu yazıda 45 yaşında bayan hastada başağrısı, bulantı ve kusma sonrası spontan oluşan karotiko-kavernöz fistül olgusu sunulmaktadır.

Sonuç: Karotiko-kavernöz fistül acil serviste nadir karşılaşılabilecek, tanı konması güç, düşünülmesi gereken, erken tanı ve tedavi ile düzeltilebilecek bir hastalıktır.

Anahtar Kelimeler: Carotid-cavernous fistula, emergency department

Geliş Tarihi: 14.02.2013 Kabul Tarihi: 19.07.2013

\section{Giriş}

Karotiko-kavernöz sinüs fistül (KKF), internal veya eksternal karotis arterle kavernöz sinüsün anormal bir bağlantı oluşturması sonucu oluşur (1-3). Bu lezyonlar anjiografik olarak direk-dural, patojenik olarak spontan-travmatik, hemodinamik olarak yüksek-düşük akımlı olarak sınıflandırılabilir $(1,2)$. Angiografik olarak Tip A fistüllerde internal karotis arter (ICA) ile kavernöz sinüs arasında direk şant vardır. Tip B ICA' nın meningeal dalı ile kavernöz sinüs, Tip C eksternal karotis arterin (ECA) meningeal dalı ile kavernöz sinüs Tip D'de ise ECA ve ICA'nın meningeal dalı ile kavernöz sinüs arasında fistül vardır $(1,3,4)$. B, C, D tiplerinde dural şant vardır (2). Spontan KKF'ler genellikle indirek ve idiopatiktir (4). Spontan kapanma olabilirken (1, 4) \%20-30 oranında kalıcı nörolojik hasara yol açar (3). 50 yaş üstü bayanlarda sık gözlenir ve birlikte hipertansiyon sıktır (1, 4). Travmatik fistüller olguların yaklaşık 3/4 ünden sorumludur ve genç erkeklerde daha sık gözlenir (5). 
Hastalardaki klasik triad orbital üfürüm, kemozis ve pulsatil egzoftalmidir (5). Bunun dışında görme keskinliğinde azalma, göz motor sinir parezisi, trigeminal nöropati, fasial sinir paralizisi, diplopi, göz hareketlerinde azalma, nadiren intrakranial kanama gözlenebilir (5-8). Olguların çoğunluğu kırmızı göz nedeniyle hastaneye başvurur. Konjonktivit, orbital sellülit, tiroid oftalmopati, sklerit, orbital pseudotümör veya ilaç kullanımına bağı allerji gibi durumlarla karışabilmektedir (3).

Spontan karotikokavernöz fistülde etyoloji tam olarak bilinmemekle birlikte kavernöz sinüs lateral duvarında meydana gelmiş arterio venöz malformasyon rüptürü sonucu geliştiği düşünülmektedir (4). Gebelik, ateroskleroz, hipertansiyon, menopoz sonrası hormonal değişimler, diyabetes mellitus, Ehler-Danlos Sendromu, psödoxantoma elasticum gibi hastalıklarda görülme sıklığı artmıştır $(3,4)$.

Amacımız acil serviste karşılaştığımız karotikokavernöz fistülü olan bir hasta ile literatürü gözden geçirerek, tartışmaktır.

\section{Olgu Sunumu}

45 yaşında bayan hasta gece baş ağrısı, kusma sonrası sol gözde ağrı, kızarıklık, görme bulanıklığı ve gözün öne doğru büyümesi şikayeti ile başvurduğu devlet hastanesinden orbital selülit ön tanısı ile ileri tetkik ve tedavi amacıyla acil servisimize sevk edildi. Acil servisimize kabul edilen hastanın migren dışında bilinen bir hastalığı ve yakın zamanda geçirilen travma hikayesi yoktu. Bulantı ve baş ağrısı sonrası 3-4 kez kusmanın ardından sol gözünde şişlik, görme bulanıklığı ve sol gözünün öne doğru çıktığı öğrenildi. Hastanın travma, insektisid sokma, bayılma, ekstremitelerde güçsüzlük öyküsü yoktu.

Fizik muayenesinde genel durumu iyi GKS:15, koopere ve oryante idi. Vital bulguları; Tansiyon Arteryel:180/90, nabız:64, solunum sayısı:12, ateş: 36.4 idi. Baş-boyun muayenesinde sol göz kapağı ödemli ve ekimotikti (Resim 1). Sağ gözde ışık refleksi alınırken sol gözde ışık refleksi alınamadı. Sol gözde konjuktival kemozis, kornea ödemi, göz hareketlerinde kısıtlılık tespit edildi. Tansiyon oküler sağ gözde 12 mmHg iken sol gözde 30 mmHg olarak ölçüldü. Diğer sistem muayeneleri normaldi.

Hastaya tetkik olarak hemogram, aPTT, PT-iNR, biyokimyasal testlerle birlikte tanı amaçlı orbita bilgisayarlı tomografi (BT) ve serebral BT angiografi istendi. Serebral BT angiografide sol gözde karotikokavernöz fistül tespit edilmesi üzerine (Resim 2) cerrahi müdahale ve detaylı göz muayenesi için Göz Hastalıkları ve Nöroşirürji konsültasyonu istendi. Acil servisteki muayene ve konsültasyonlar sonucunda hastanın kliniği ve BT sonucunun karotikokavernöz fistül ile uyumlu olduğuna karar verildi ve hastada girişimsel radyoloji planlanarak Nöroşirürji kliniğine yatış verildi.

\section{Tartışma}

Karotikokavernöz fistülün tanısında klinik önemlidir (9). Baş ağrısı, kulak çınlaması, pulsatil veya nonpulsatil proptozis, schlemm kanalında hemoraji, geniş̧lemiş episkleral venler, kemozis, diplopi, sekonder glokom, görme kaybı izlenebilir $(3,9)$. Üfürüm tanı koydurucudur ancak duyulması zordur (3). Bizim olgumuzda başağrısı, görme kaybı, diplopi ve kemozis tespit edildi.

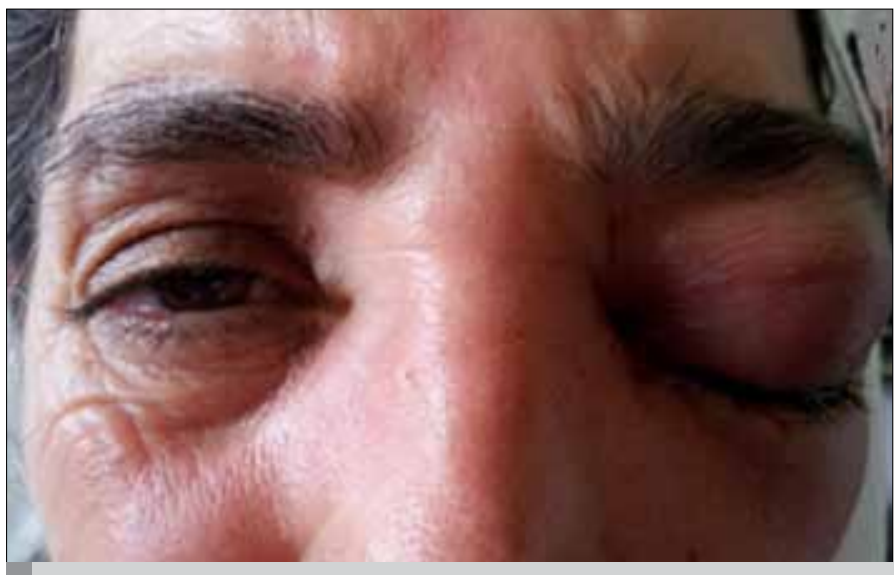

Resim 1. Sol göz kapağında ödem ve ekimoz

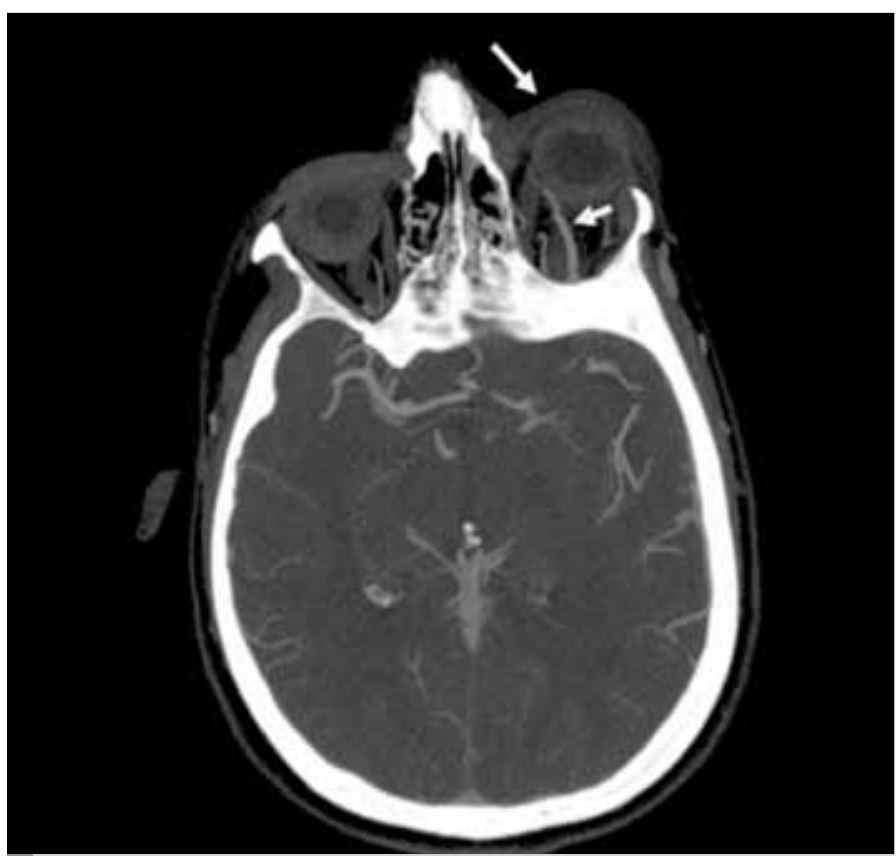

Resim 2. BT angiografide propitozis (uzun ok), süperior oftalmik ven dilatasyonu ve periorbital venlerde dilatasyon (kısa ok) ile yumuşak dokuda ödem görünümü

Sekonder glokom sık görülen bir komplikasyondur (3). Episkleral venöz basınç yüksekliğine bağlı intraoküler basınç yükselebilir (10). Koroid konjesyonu sonucunda iris lens diyaframının öne doğru yer değiştirmesi ile açı kapanması glokomu ve pupiller blok da görülebilir (3). Uzun süre müdahale edilmeyen ya da tanısı geciken olgularda retinal iskemiye bağlı neovasküler glokom gelişebilir $(3,10)$. Nadiren de olsa bazı hastalarda venöz staza bağlı intraretinal hemorajiler, santral retinal ven tıkanıklığı görülebilir (10). Bizim olgumuzda intraokuler basınç sol gözde daha yüksek ölçüldü.

Oküler motor sinirlerin tutulumu sonucu oftalmopleji oluşabilir ve en sık 6. kranial sinir tutulumu izlenir $(3,5,10)$. Ayrıca ekstraoküler kaslarda genişleme sonucunda göz hareketlerinde de kısıtlılı görülebilir $(3,5,10)$. Bizim hastamızda intraoküler basınç yüksekliği, oküler hareket kısıtlılığı mevcuttu. 
KKF'de erken tanı önemlidir. Tanı gecikmesi durumunda serebral venlere retrograd venöz drenaj gelişmiş olgularda \%30-40 oranında serebral hemoraji gibi ciddi komplikasyonlar görülebilmektedir (3, 10). Özellikle spontan karotikokavernöz fistüllerde klinik daha sessiz olduğu için tanı geç konabilmektedir $(3,10)$. Karotikokavernöz fistül tanısı klinik ve anjiografik inceleme ile konur $(3-5,10)$. Klinikte tanının en önemli basamağı şüphedir (3). Klinik şüphede hastaya noninvaziv olarak orbita doppler ultrasonografisi, orbita tomografisi ve magnetik rezonans ile orbitanın incelenmesi yapılabildiği gibi kesin tanı olarak orbita veya serebral anjio BT kullanılabilir $(3,5,10)$.

Spontan karotikokavernöz fistüllerde; görme kaybı, diplopi, üfürüm ve baş ağrısı, ilerleyici proptozis ve yüksek seyreden göz içi basıncının varlığı tedavi endikasyonudur (3). Travmatik fistüllerde; ilerleyici görme kaybı, tolere edilemeyen üfürüm ve baş ağrısı, kavernöz sinüsün arkasına doğru genişleyen travmatik anevrizma, intrakranial hematoma bağlı hemipleji, kortikal venöz drenajın bozulması, epistaksis ve göz içi basıncının 40 mmHg üzerinde olması gibi durumlar acil tedavi gerektirir $(3,10)$.

Karotikokavernöz fistülde tedavi oküler semptomları düzeltmeye yöneliktir. Düşük akımlı dural fistüllerde spontan tromboz olabilir. Bu nedenle invaziv tedaviden önce bir süre gözlem önerilmektedir (10). Tedavi de travma sonrası gelişen yüksek akımlı fistüllerde sıklıkla anjiografi eşliğinde balonla fistül kapatılmaya çalışılmaktadır (3, 4, 10). Dural kaynaklı düşük akımlı ve çoğunlukla spontan gelişen fistüllerde fistülün arteriyel ve venöz yoldan embolizasyon ve trombozis işlemi yapılmaktadır $(3,7,10)$. Balon veya embolizasyon işlemi transarteriyel olarak ICA içinden veya transvenöz olarak inferior petrosal sinüsten ya da süperior oftalmik ven yoluyla yapılmaktadır $(3,4,10)$. KKF'ün bütün tiplerininin tam kapanmasından sonra prognoz iyidir $(3,7,10)$. Nadiren fistül kapatıldıktan sonra semptomlar bölgedeki lokal ödem ve basınç artışı nedeniyle kötüye gidebilmektedir. Bu etkiler kısa sürelidir ve günler içerisinde düzelme gösterir $(3,4)$.

\section{Sonuç}

Acil servislere görme bulanıklığı, çift görme, kızarıklık, proptozis ve/ veya görme kaybı ile başvuran hastalarda acil servis hekimlerinin spontan veya travmatik karotikokavernöz fistül varlığını düşünmeleri gerektiğini vurguladığımız bu olguda olduğu gibi erken dönemde klinik şüphe sonrası hastanın gerekli radyolojik incelemesinin yapılıp göz hastalıkları ve nöroşirürji konsültasyonları istenerek hastada olası ciddi komplikasyonların gelişmesinin önüne geçilebilineceği düşünülmüştür. Bu konuda acil servis hekimlerine büyük görev düşmektedir.

Hasta Onamı: Yazılı hasta onamı bu çalışmaya katılan hastadan alınmıştır.

Hakem değerlendirmesi: Dış bağımsız.
Yazar Katkıları: Fikir - M.G., M.Y.; Tasarım - M.G., Ö.D.A.; Denetleme M.Y.; Malzemeler - M.G., Ö.D.A.; Veri toplanması ve/veya işlemesi - E.E.; Analiz ve/veya yorum M.G., M.A., M.Y.; Literatür taraması - M.G., E.E.; Yazıyı yazan - M.G.; Eleştirel İnceleme - M.Y., M.A.

Çıkar Çatışması: Yazarlar herhangi bir çıkar çatışması bildirmemişlerdir.

Finansal Destek: Yazarlar bu çalışma için finansal destek almadıklarını beyan etmişlerdir.

Informed Consent: Written informed consent was obtained from the patient who participated in this study.

Peer review: Externally peer-reviewed.

Author contributions: Concept - M.G., M.Y.; Design - M.G., Ö.D.A..; Supervision - M.Y.; Materials - M.G., Ö.D.A.; Data Collection and/or Processing - E.E.; Analysis and/or Interpretation - M.G., M.A., M.Y.; Literature Review - M.G., E.E.; Writer - M.G.; Critical Review - M.Y., M.A.

Conflict of Interest: The authors declared no conflict of interest.

Financial Disclosure: The authors declared that this study has received no financial support.

\section{Kaynaklar}

1. Karadag R, Bayraktar N, Kirbas I, Durmus M. Unilateral, Indirect Spontaneous Caroticocavernous Fistula with Bilateral Abduction Palsy. Indian J Ophthalmol 2011; 59: 336-7. [CrossRef]

2. Uludüz D, Gündüz A, Erkol G, Saip S. Carotid-Cavernous Fistula Arising and Regressing Spontaneously: A Case Report. New/Yeni Symposium Journal 2007; 5: 3-6.

3. OralY, Özdil ŞE, Özkurt YB, Arsan AK, Karadag O, Dogan ÖK. Spontan Karotiko-Kavernöz Sinüs Fistülü Olgusuna Yaklaşım. T Oft Gaz 2008; 52832.

4. Chaudhry IA, Elkhamry SM, Al-Rashed W, Bosley TM. Carotid Cavernous Fistula: Ophthalmological Implications .Middle East African Journal of Ophtalmology 2009; 16: 57-62. [CrossRef]

5. Kaplan JB, Bodhit AN, Falgiani ML. Communicating Carotid-Cavernous Sinus Fistula Following Minor Head Trauma. International Journal of Emergency Medicine 2012; 5: 1-5. [CrossRef]

6. Horie N, Morikawa M, So G, Hayashi K, Suyama K, Nagata I. Direct Arteriovenous Fistula At The İnferolateral Trunk Mimicking Carotid Cavernous Fistula Without Involving The Cavernous Sinus: A Case Report. Acta Neurochir 2012; 154: 465-9. [CrossRef]

7. Miller NR. Diagnosis And Management of Dural Carotid-Cavernous Sinus Fistulas. Neurosurg 2007; 23: 1-15.

8. Hekimoğlu B, Bavbek M, Men S, Aykan P, Çakar B. Detachable Balloon Embolization In Treatment Of Carotid-Cavernous Fistula: A Case Report. Türk Noroşirürji Dergisi 1994; 4: 98-102.

9. Şahin A, Kamış Ü, Albayram MS, Kerimoğlu H, Işlak C. Travmatik Karotikokavernöz Fistül: Olgu Sunumu. MN Oftalmoloji 2007; 14: 144-6.

10. Kocaoğlu FA, Katırcıoğlu YA, Ünlü C, Ünlübay D, Duman S. Karotikokavernöz Fistül Olgu Sunumu. MN Oftalmoloji 2005; 12: 168-70. 